\title{
Women in Popular Korean Drama: In Need of Embracing 'Cyborg' Feminism
}

\author{
Kamna Singh \\ Assistant Professor of English, Punjab Engineering College, Chandigarh \\ E-mail: kamnasingh@pec.edu.in
}

\begin{abstract}
Women in Korean television dramas are depicted as modern, multifaceted, feminine and feminist. However, while rich, varied and complex on the surface; the female characters reveal their identities as remaining bound by traditional notions of what it means to be female, albeit a feminist female. Previous studies in this area are few and far between and do not focus on recently aired shows. As Korean dramas play a vital, conscious and subconscious role in shaping the individual and society, such research is the need of the hour; more so as the global popularity of these dramas has made them the unofficial cultural ambassadors of Asia. Through the lens of Donna Haraway's feminist theory, this paper applies qualitative textual analysis to selected Korean dramas aired in the summer of the year 2020. It finds that female characters in these shows need to embrace what Haraway calls 'cybernetic identity'. Using the symbol of the cyborg which is gender-neutral, these characters need to embrace 'multigenderism' without concern for what 'category' this will put them in, thus allowing their self-expression without the binary constraints of being 'male' or 'female' or the fear of being 'something in between genders'. This research aims to further Gender Studies and inspire depictions of characters devoid of any preconceived notions in Korean dramas.
\end{abstract}

Keywords: Postmodern Feminism, Haraway, Korean Drama, Qualitative Textual analysis

\section{Introduction}

'Hallyu' (Korean Wave) or the rise of international interest in Korean popular culture, especially television dramas, in a media space hegemonized by 'Western' content, has become an unofficial, worldwide ambassador for Asian identities. Among the plethora of studies on Hallyu, what remains relatively unchartered is how the semiotic terrain of Korean dramas effects gender perceptions and is in turn, affected by these.

The paradigms of gender presentations and politics come into play as Korean dramas are the sites of and for interactions between the fictional and factual worlds of the Twentieth and Twenty-first century traditional, modern and hybrid cultures which have manifested in these dramas, a gaming ground for gender play that influences audiences at both conscious and subconscious levels. This phenomenon makes for a complex palimpsest text.

This paper looks at a selection of Korean dramas aired in the summer of 2020 (namely, 'Fatal Promise', 'Born Again', 'How to Buy a Friend', 'Once Again', and 'Men are Men') with respect to these concerns and proposes that gender definitions and presentations of the genders as

(c) AesthetixMS 2020. This Open Access article is published under a Creative Commons Attribution Non-Commercial 4.o International License (http://creativecommons.org/licenses/by-nc/4.o/), which permits non-commercial re-use, distribution, and reproduction in any medium, provided the original work is properly cited. For citation use the DOI. For commercial re-use, please contact editor@rupkatha.com. 
antagonistic binaries needs to be if not obliterated totally, then considerably minimized so that the audiences can learn to identify, appreciate and identify with individuals as fluid entities, without any concern for categorizations. Just as a cyborg is a distinct entity, neither male nor female, but free to act as either male, or female, or both, or neither; similarly, should individuals be allowed to break free of social/ cultural definitions and pre-significations of their gender; and be free to assume whatever gender identities they choose at whatever time they choose; without fear or prejudice.

Qualitative Textual Analysis is employed to examine the selected multimodal texts and examine the interrelationships among the medium, text, subtext, and context by expositing, as Brennen (2013) defines, how "concepts, ideas, themes and issues" are presented in the "social practices, representations, assumptions and stories" in these dramas.

This research applies Donna Haraway's views as originally exposited in 'A Cyborg Manifesto' and suggests that although Korean dramas have tried to subvert gender stereotypes and caricatures and/ or make them redundant; they have a long way to go and the symbol of the cyborg is a useful model for future reference. This idea is keeping in line with the postmodern celebration of pastiche, intertextuality, free play of significations and unfettered individual expression as key modes of resistance and contrapuntal discussion in a still largely conventiondriven society.

\section{A Hybrid Modernity}

Korean dramas present a hybridization of cultures resulting in narratives that are widely palatable to global masses in their depiction of identifiable fantasy worlds. While their 'Eastern' viewers are drawn to their Confucian family and human values, the modern presentation of plots, characters and settings appeal to 'Western' viewers looking for entertainment with a familiar yet foreign flavour. Their female characters such as Cha Yung-Dong ('Fatal Promise'); Haeun/ Sa-Bin ('Born Again'); Eom Se-Yoon ('How to Buy a Friend'); Jang Ok-Boon, Ga-Hee, Na-Hee, Da-Hee etc. ('Once Again'); and Seo Hyun-Joo ('Men are Men') are manifestations of this innovation.

Korean dramas have thereby not only succeeded in igniting and sustaining a conversation among apparently polarised cultures but also, by doing so, facilitated the rise of a new hybrid 'modern' culture. Lin and Tong define what it means to be 'modern' in Korean dramas by explaining that this signifies the existence of modern or 'Western' qualities alongside traditional or 'Eastern' elements (100). They specify that "Asian 'modernity' is not simply a replication of Western modernity, but rather an idealized concept associated with materialism, consumerism, female emancipation, and individualism" (122).

\section{Being Modern Feminists at the Cost of Becoming Postmodern Individuals}

In reflection of this precarious ideological balance, women in Korean dramas are overtly depicted as quintessentially 'modern', multifaceted, feminine and feminist. They however remain bound by notions of what it means to be 'modern' females, unable to progress to becoming postmodern individuals.

This research finds the 'modernity' of Korean dramas, the very key to their success, ironically hindering their evolution. This 'modernity' has excelled in presenting female characters in a feminist manner with such commercial (and in many cases, critical) success that these characters have become fossilized and refuse to make a natural progression to their postfeminist 
selves. They remain 'modern' in a postmodern world, trapped in their self-created modern mythologies of 'everywoman' (e.g. Da-Hee), 'nurturing earth mother'(e.g. Sa-Bin/ Haeun), 'woman with a mind of her own' (e.g. Seo Hyun-Joo), 'woman on a mission' (e.g. Cha Yung-Dong), 'emancipated homemaker' (e.g. Jang Ok-Boon), 'independent divorcee' (e.g. Na-Hee), 'older woman in a relationship with a younger man' (e.g. Ga-Hee), popular all-rounder (e.g. Eom SeYoon) and so forth; unable to escape their own 'success' stories.

\section{Haraway’s Postmodern, Postfeminist Cyborg versus Modern Feminism}

Modern feminism defines female as that which is 'not male', which has been branded as 'other' by the male. The woman is a socially created being and womanhood exists because men have defined it into existence by associating all the qualities they disdain and reject in themselves as being feminine.

Modern feminism views 'female' as equal or 'superior' to 'male'. In the mid Nineteenth to early Twentieth centuries, it encouraged females to imitate 'male' behaviour (still seen in shows like 'Fatal Promise' and 'Men are Men'). In the mid Twentieth century, females were encouraged to become 'better than men' (e.g. 'How to Buy a Friend' and 'Once Again'). The late Twentieth century gave the idea that females must embrace their unique 'femaleness' (e.g. 'Born Again' and 'How to Buy a Friend'.) However, the difference between 'male' and 'female' remained clearly demarcated. Those 'in between' these sacrosanct genders were relegated to the realm of the Queer movement and the 'othering' of genders endured. This also led to the rise of countermovements such as Masculism and Reverse Feminism which viewed modern Feminist agency in a pejorative light.

To counter this ideology, Haraway conjured up the symbol of the cyborg. As the cyborg has no 'divine' origin and is free of natural biology, it is also free of the biological ideas of male and female. Haraway advocated a reconstruction of identity, devoid of naturalism and taxonomy and defined instead, by affinity. She insisted that anyone could choose to remain outside the bounds of any category or choose to join/ construct his/ her own groups.

\section{Evidences (?) of Cyborg Identities in Korean Dramas}

A woman of colour "might be understood as a cyborg identity, a potent subjectivity synthesized from fusions of outsider identities and in the complex political-historical layering of her 'biomythography."' (Haraway, 200o)

Overtly, Korean dramas embody Intersectionality by representing Korean women (that is, women who are not white), with rich layers of contextual subjectivities. They appear to be, what Haraway calls, women with 'cyborg identities'.

Furthermore, these dramas tend to idealize different categories of 'modern women', presumably, to pay homage to the 'modern woman'. For instance, Cha Young-Dong manages to single-handedly take down a powerful corporate house; Eom Se-Yoon excels equally in studies, extra-curricular activities, good looks, popularity and strength of character; Jang Ok-Boon cares for a large family; Sa-Bin single-handedly stops the male lead from becoming a criminal; and Seo Hyun-Joo marries herself in a public ceremony to declare her vow to love and care for herself as no man can. Such evidences are used by researchers to praise the depiction of 'strong' women in Korean dramas. 
Additionally, there are evident conscious efforts by Korean screenwriters, of which an overwhelming ninety percent are female, to provide multiple and unconventional female perspectives and pay homage to the female gaze by creating romantic scenarios among the-girlnext-door characters and highly eligible male characters (e.g. 'Born Again', 'Fatal Promise', 'Once Again' and 'Men are Men'); and allowing the female characters to converse about concerns and experiences unique their daily lives such as earning a living, childrearing, health problems etc. It is thus no surprise that Korean dramas farewell in the Bechdel test (which outlines the criteria for texts to be considered feminist).

Moreover, it may be argued that Korean dramas have pioneered a restructuring and deconstruction of masculinity in the presentation of their male lead actors who are termed as 'pretty boys'(in all dramas, including the five under study) to refer to their refined, feminized appearance. This new breed of men seemingly embodies the best of both masculinity and femininity. According to Jung (2011), "the pretty boy can satisfy complex human desire because they possess both masculine and feminine traits." Shuri (2015) explains "They have certain physical features i.e. tall, smooth skin, silky hair, and they are fashionable and romantic". The well-groomed and sensitive 'pretty boy' may be interpreted as a sign of the acceptance of feminine principle by males in open acknowledgement of their admiration for it. So should the above evidences be viewed as proofs of 'positive' and 'progressive' depictions of genders in Korean dramas? The answer is, no.

\section{An Absence of Cyborg Identities}

The cyborg identity may be defined as an identity devoid of any preconceived notions of feminine, feminist or masculine behaviour and envisions individuals as being mentally and emotionally free of their biological sex to adopt any identity, any variation of identity or any mix of identities as, when and as frequently they choose. This is in opposition to the views of traditional feminism that operate under the essentialist, albeit strategic essentialist, division of 'male' and 'female'. Late stages of modern feminism allow for subsets of categories within genders such as woman of colour, financially oppressed woman and so forth but once again labels and categorizes individuals.

On the other hand, "a cyborg theory of wholes and parts," moves beyond "identity politics" (Haraway, 2000) and value judgments to embrace fluid identities. It is a postfeminist theory that embraces all identities and characteristics in complete rejection of body categorization, body shaming and body politics.

From this perspective, Korean dramas have highly limited representation of female lead characters (role models for viewers) who belong to mainstream culture, namely, middle class, educated, of at least (culturally) average appearance and age ranging from late teenage to approximately thirty-five years of age. The idealised depictions of these female characters as modern feminists is a fallacy that creates and perpetuates unrealistic ideals of womanhood, or rather individual hood, that create tensions within individuals, in households and in societies when biological females fail to measure up to these fictionalized 'feminist' standards.

There is a lack of a representation of women who have experiences and identities differing from this narrowly defined subset which may cause women to be double, triple or even more marginalized. Korean dramas remain unable to embrace postfeminist heterogeneous identities. 
Also, the female lead characters are invariably portrayed as non-materialistic, loyal and principled. Thinkers like Taeyon (2003) postulate that regarded as subject-less bodies and valued mainly for their procreative and domestic abilities, the sexual liberation of females has been regarded as dangerous for the perpetuation of capitalist patriarchal lineages so female chastity and fidelity remain their most prized attributes. Therefore, Korean dramas continue to either pretend that female sexuality is non-existent (e.g. 'Born Again', 'Once Again', 'Men are Men') or show the negative consequences of sexual empowerment affecting the woman, who is of course, never the female lead character. For instance, in 'Fatal Promise', while the female lead character is shown as being fully empowered (and having no sexual desire), a non-lead female character Oh Hye-Won is rendered barren after choosing to abort the pregnancy caused by pre-marital sex with the male lead character. She is socially censured and repeatedly verbally abused by the other female characters in the show for having a "dirty body". However, the male lead character Kang Taein is shown as suffering from no censure whatsoever and remaining an eligible bachelor. In 'How to Buy a Friend', the friend of the female lead character is socially ostracised after a video of her being inappropriately touched is made public. Her subsequent suicide is avenged by her boyfriend and two other male characters who also manage to 'protect' the female lead character from a similar fate. Despite the female lead character having every imaginable quality ranging from good looks to artistic talent to academic brilliance, she is subaltern to the male lead who is average in every way but manages to save the day, every day.

Addressing the iconic 'pretty boy', this research finds that far from being a cyborg identity that celebrates the erasure of the boundaries between femininity and masculinity, the 'pretty boy' creates and propagates a revised masculinity. This is a masculinity which promotes the beauty, fashion and luxury consumption industries that hitherto targeted mostly females and are looking for new customers in a near-saturated marketplace. Jung (2010) asserts that the 'pretty boy' embodies a neo-masculinity because he is of a privileged gender still identifiable as 'male'. Jung (2011) argues this neo-masculinity is "a hybrid product constructed through the transcultural amalgamation of South Korea's traditional 'Seonbi' masculinity (which is heavily influenced by Chinese Confucian wen masculinity), Japan's 'Bishonen' (pretty boy) masculinity, and global Metrosexual masculinity".

Hence, the rise of the 'pretty boy' must be understood as a capitalist rather than feminist triumph. It is only the appearance (refined by consumption of goods and services) that makes the pretty boys feminine. In every other way, they are clearly demarcated from and disassociated with traits associated with femininity and queerness. Masculine superiority is maintained through possession of highly valued social attributes; display of intellectual and physical superiority; action scenes featuring fighting strength and skills and above all a psychological 'toughness' and repeated iterated desire to 'protect' the female characters. For instance, in 'Born Again', the two male lead characters Cheon Jon-Beom and Kim Soo-Hyeok are good-looking, wealthy, talented and assertive while the female lead character Sa-Bin, the object of their desire, is average looking, middle-class, empathetic and in constant need of their 'protection'. Even critics like Ngo (2015, p. 151) who defend gender presentation in Korean dramas, admit that the masculine characters maintain a paternal position in interpersonal relationships.

\section{Conclusion}

The idea that everything is naturally divisible into polar opposites has solidified gender categorization. It is based on the notion that gender has an inherent, fixed signification based on certain characteristics. In Korean dramas, even in the summer of 2020, far from developing 
'cyborg identities', the female characters remain bound by narratives to existing categories of 'modern' womanhood.

Haraway's symbol of the cyborg is not a 'genderless' or post-gender statement. As she herself exposits, her "intention is to challenge the necessity for categorization of gender". Haraway advocates 'multigenderism' and says that as gender constructs are still prevalent in society, it is difficult for society to abandon them altogether. Indeed, such an act may cause identity crises rather than identity resolution. On the other hand, having the freedom to pick and choose aspects of one's own gender identity allows individuals to express themselves without constraints. This is the postfeminist thought that in the opinion of this research, needs to embraced by Korean dramas as cultural ambassadors and influencers of collective and individual consciousness and subconsciousness.

Thinkers such as Linda Alcoff define 'female' as a position rather than a characteristic. This explains real-life experience while allowing for its change. The position and presentation of characters in Korean dramas needs to be re-thought, re-formulated and depicted with seamless fluidity to encourage the same in the viewers and transform Korean dramas from instruments of cultural propagation to agents of cultural evolution.

\section{References}

\section{Primary}

Choi Yoon-Suk (Director). (2020). Men are Men. [Television Drama]. South Korea: KBS 2.

Haraway, Donna. (2000). A Cyborg Manifesto: Science, Technology, and Socialist-Feminism in the Late Twentieth Century. In N. Badmington (ed.), Posthumanism. New York: Palgrave. 69-84.

Jin Hyung-Wook (Director). (2020). Born Again. [Television Drama]. South Korea: KBS 2.

Kim Shin-II (Director). (2020). Fatal Promise. [Television Drama]. South Korea: KBS 2.

Lee Jae-Sang (Director). (2020). Once Again. [Television Drama]. South Korea: KBS 2.

Yoo Young-Eun. (Director). (2020). How to Buy a Friend. [Television Drama]. South Korea: KBS 2.

\section{Secondary}

Alcoff, Linda. (1988). Cultural Feminism Versus Post-structuralism: The Identity Crisis in Feminist Theory. Signs: Journal of Women in Culture and Society. 13 (2). 105-36.

Brennen, B. S. (2013). Qualitative Research Methods for Media Studies. New York: Routledge.

Gandy, Matthew (2010). The Persistence of Complexity: Re-reading Donna Haraway's 'Cyborg Manifesto'.AA Files. 6o (6o). 42-44.

Haraway, Donna (2004). Cyborgs, Coyotes, and Dogs: A Kinship of Feminist Figurations and There are Always More Things Going on Than You Thought! Methodologies as Thinking Technologies. In The Haraway Reader. New York: Routledge. 321-341.

Jung, S. (2010). Chogukjeok Pan-East Asian Soft Masculinity: Reading Boys Over Flowers, Coffee Prince and Shinhwa Fan Fiction. In D. Black, S. Epstein \& A. Tokita (Eds.), Complicated Currents: Media Flows, Soft Power and East Asia. Australia: Monash University ePress. 
7 | Women in Popular Korean Drama: In Need of Embracing 'Cyborg' Feminism

Jung, S. (2011). Korean Masculinities and Transcultural Consumption: Yonsama, Rain, Oldboy, K-Pop Idols. Hong Kong: Hong Kong University Press.

Lin, Angel, and Avin Tong. (2008).Re-Imagining a Cosmopolitan 'Asian Us': Korean Media Flows and Imaginaries of Asian Modern Femininities. InChua Beng Huat and Koichi Iwabuchi (Eds.) East Asian Pop Culture: Analysing the Korean Wave. Hong Kong: Hong Kong University Press. 91-126.

Ngo, T. H. (2015). Korean Masculinity in TV Dramas and Local Fantasies: A Case Study of Full House and its

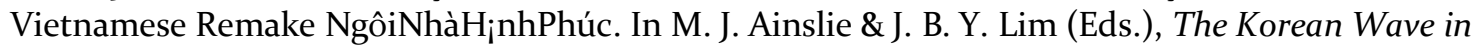
Southeast Asia: Consumption and Cultural Production. Malaysia: Strategic Information and Research Development Centre. 133-154.

Shuri, M. G. T. (2015). Imaginary ‘Asia’: Indonesian Audience’s Reflexivity on K-dramas. In M. J. Ainslie \& J. B. Y. Lim (Eds.), The Korean Wave in Southeast Asia: Consumption and Cultural Production. Malaysia: Strategic Information and Research Development Centre. 75-94.

Taeyon, Kim. (2003). Neo-Confucian Body Techniques: Women's Bodies in Korea's Consumer Society. Body and Society.9 (2). 97-113.

Weir, Allison. (1996). Sacrificial Logics: Feminist Theory and the Critique of Identity. New York: Routledge.

Dr. Kamna Singh is an Assistant Professor of English at Punjab Engineering College, Chandigarh. She is a Ph.D. and an M. Phil (Gold Medalist) in English from Panjab University. Her areas of interest include Literary Theory, Cultural Studies and English Literature. She has publications in highly reputed, including Scopus indexed and UGC listed journals. 